\title{
ESTADO E TERCEIRO SETOR: AS NOVAS REGULAÇÕES ENTRE O PÚBLICO E O PRIVADO NA GESTÃO DA EDUCAÇÃO BÁSICA BRASILEIRA
}

\author{
Vera Maria Vidal Peroni* \\ Regina Tereza Cestari de Oliveira* \\ Maria Dilnéía Espíndola Fernandes ${ }^{* * *}$
}

\begin{abstract}
RESUMO: Este artigo analisa as conexões entre o público e o privado, no contexto particular do capitalismo de redefiniçóes no papel do Estado, enfatizando a relação entre o diagnóstico neoliberal, incorporado pela terceira via, de que o responsável pela crise é o Estado, e as estratégias de transferência da execução das políticas sociais do Estado para a sociedade civil. Nessa configuração, focaliza o projeto de reforma do Estado brasileiro, que aponta a substituição da administração pública burocrática pela administração pública gerencial e remete à sociedade civil, de modo especial, ao terceiro setor, o encargo pelos serviços sociais e científicos. Assim, questiona-se o deslocamento do foco da participação da sociedade, do controle social para a execução dessas políticas e procura-se discutir as decorrências dessas alterações para as políticas de gestão da educação básica, principalmente, no que concerne à construção da gestão democrática.
\end{abstract}

Palavras-chave: Estado. Público e privado. Terceira via. Terceiro setor. Gestão da educação básica.

* Doutora em Educação e professora do Programa de Pós-Graduação em Educação da Universidade Federal do Rio Grande do Sul (UfRGS). E-mail: veraperoni@yahoo.com.br

* Doutora em Educação e professora do Programa de Pós-Graduação em Educação da Universidade Católica Dom Bosco (UCDB).E-mail: reginacestari@hotmail.com

* Doutora em Educação e professora do Programa de Pós-Graduação em Educação da Universidade Federal de Mato Grosso do Sul (UfMs).E-mail: mdilneia@uol.com.br

Educ. Soc., Campinas, vol. 30, n. 108, p. 761-778, out. 2009

Disponível em <http://www.cedes.unicamp.br> 
Estado e terceiro setor: as novas regulações entre o público e o privado...

The State and THE THIRD SECTOR: THE NEW REgUlations BeTWEeN PUBLIC AND PRIVATE ORGANIZATIONS IN BRAZILIAN BASIC EDUCATION MANAGEMENT

ABSTRACT: This paper analyzes the connections between public and private organizations within the redefinitions of the role of the State in the context of capitalism. It emphasizes the relationship between the neoliberal diagnosis, incorporated by the Third Way, according to which the State is responsible for the crisis. It also considers the strategies of transference of the State's social policies to civil society. It focuses on the Brazilian reform project, which includes the replacement of the bureaucratic public management by a new public management and transfers the responsibility for social and scientific services to the civil society, mainly to the third sector. It thus questions the change of focus of society's participation and the social control to enforce these policies, as well as the consequences of such changes for basic education management policies, especially regarding the construction of a democratic management.

Key words: State. Public and private organizations. Third way. Third sector. Basic education management.

\section{Introdução}

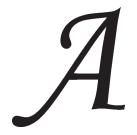

parceria público-privada e as implicaçóes para a gestão da escola pública ocorrem em um contexto particular do capitalismo que, após uma grande fase de expansão que se iniciou no pós-guerra, vive um período de crise ${ }^{1}$ e as suas principais estratégias de superação - neoliberalismo, globalização, reestruturação produtiva e terceira via - redefinem o papel do Estado, principalmente para com as políticas sociais, com profundas consequências para a relação público-privada.

Neste contexto, tal relação ganha novos contornos, não apenas passando para o setor lucrativo, mas também para o público não-estatal a execução das políticas, ou ainda mudando a lógica de gestão do público, tendo como parâmetro o privado, por julgá-lo padrão de eficiência e produtividade, com profundas consequências para a construção da gestão democrática da educação (Peroni, 2008b).

Assim, a parceria público-privada deve ser analisada situada no tempo e no espaço e não em abstrato. Neste período particular do 
capitalismo de redefinições no papel do Estado, são muitas as dimensões da relação público-privada. Como afirma Dale (1994, p. 112): “(...) o que está envolvido não é tanto uma deslocação direta do público para o privado, mas um conjunto muito mais complexo de mudanças nos mecanismos institucionais através dos quais são regulados o que continuam a ser essencialmente sistemas educativos estatais".

As novas fronteiras entre o público e o privado materializam-se de diversas formas. O destaque neste artigo será dado para dois movimentos: a alteração da propriedade (público não-estatal) e o que permanece na propriedade estatal, mas passa a ter a lógica do mercado, reorganizando os processos de gestão (quase-mercado).

A parceria público-privada no contexto da terceira via/terceiro setor

A análise destes processos requer um estudo do movimento do real no contexto social atual e, principalmente, da influência das teorias neoliberal e terceira via para a reconfiguração entre público e privado, entendendo as parcerias público-privada na educação como parte deste.

As teorias neoliberal e terceira via têm em comum o diagnóstico de que o culpado pela crise é o Estado, mas propõem estratégias diferentes de superação: o neoliberalismo defende o Estado mínimo e a privatização e a terceira via, a reforma do Estado e a parceria com o terceiro setor. Ocorre que, tendo o mesmo diagnóstico de que a crise está no Estado, nas duas teorias, este não é mais o responsável pela execução das políticas sociais: o primeiro a repassa para o mercado e o segundo, para a chamada sociedade civil sem fins lucrativos.

Outra questão que se diferencia nas teorias é a concepção de democracia. Enquanto para o neoliberalismo a democracia atrapalha o livre andamento do mercado, pois deve atender a demanda dos eleitores para se legitimar, o que provoca o déficit fiscal, para a terceira via a democracia deve ser fortalecida. Giddens (2001) fala em democratizar a democracia, mas o problema é que esta é entendida como a sociedade assumindo tarefas que até então eram do Estado, enquanto a participação significa responsabilização na execução de tarefas. Assim, verifica-se uma separação entre o econômico e o político, o esvaziamento da democracia como luta por direitos e das políticas sociais como a materialização de direitos sociais. 
Estado e terceiro setor: as novas regulações entre o público e o privado...

O entendimento de crise está na base do debate acerca das parcerias entre o público e o privado. Para autores como Antunes (1999), Mészàros (2002) e Harvey (1989, 2008), a crise não se encontra no Estado, é uma crise estrutural do capital. As estratégias de superação da crise - como o neoliberalismo, a globalização, a reestruturação produtiva e a terceira via - é que estão redefinindo o papel do Estado (Peroni, 2006).

Para a teoria neoliberal, não é o capitalismo que está em crise, mas o Estado. A estratégia, portanto, é reformar o Estado e diminuir sua atuação para superar a crise. Para a corrente neoliberal, caberá ao mercado superar as falhas do Estado. Portanto, a lógica deste deve prevalecer inclusive em si mesmo, para que ele possa ser mais eficiente e produtivo. O diagnóstico é que o Estado entrou em crise porque gastou mais do que podia para se legitimar, pois tinha que atender às demandas da população por políticas sociais, o que provocou a crise fiscal. E, também, porque, ao regulamentar a economia, restringe a livre iniciativa.

Para esta teoria, as políticas sociais são consideradas um verdadeiro saque à propriedade privada, pois além de distribuírem renda, atrapalham o livre andamento do mercado, na medida em que os impostos oneram a produção.

O papel do Estado para com as políticas sociais é alterado, pois com este diagnóstico duas são as prescrições: racionalizar recursos e esvaziar o poder das instituições, já que instituições democráticas são permeáveis às pressões e demandas da população, além de serem consideradas como improdutivas, pela lógica de mercado. Assim, a responsabilidade pela execução das políticas sociais deve ser repassada para a sociedade: para os neoliberais, por meio da privatização (mercado), e para a Terceira Via pelo público não-estatal (sem fins lucrativos). (Peroni, 2006, p. 14)

Assim, para a teoria neoliberal, está muito explícita a retirada do Estado das políticas sociais universais, a ênfase no lucro, a mercantilização da sociedade e a consequente desigualdade social. No que se refere à terceira via, a análise deve ser mais detalhada, pois, em um primeiro momento, parece ser ou muito democrática ou igual ao que propóe o neoliberalismo.

Face ao exposto, a terceira via tem o mesmo diagnóstico apontado pelo neoliberalismo de que a crise se manifesta no Estado e não no capital. Portanto, ao propor a parceria publico-privada, também reduz o papel do Estado na execução das políticas sociais, repassando 
principalmente para o público não-estatal ou terceiro setor, e o que permanece sob a esfera estatal passa a ter a lógica de mercado, que é considerado mais eficiente e produtivo.

A atual social-democracia foi batizada de terceira via por ser uma proposta alternativa ao neoliberalismo e à antiga social democracia. Como afirma Giddens (2001, p. 36):

(...) Terceira Via se refere a uma estrutura de pensamento e de prática política que visa a adaptar a social democracia a um mundo que se transformou fundamentalmente ao longo das últimas duas ou três décadas. É uma Terceira Via no sentido de que é uma tentativa de transcender tanto a social democracia do velho estilo quanto o Neoliberalismo.

Conforme Antunes (1999), a discussão sobre a terceira via ocorre quando o novo trabalhismo se apresenta como uma alternativa ao neoliberalismo de Thatcher e também à antiga social democracia. Segundo o autor, o novo trabalhismo "associa a preservação da social democracia e elementos básicos do neoliberalismo” (p. 95).

Para Giddens, (2001, p. 80), “os neoliberais querem encolher o Estado; os social-democratas, historicamente, têm sido ávidos para expandi-lo. A terceira via afirma que é necessário reconstruí-lo”. Ainda, ao ser questionado sobre o que é a terceira via, Giddens afirma que:

É fácil explicar o que é a terceira via. É um rótulo para discussões que ocorrem no mundo sobre como construir políticas de centro-esquerda, responsáveis pelas grandes mudanças na sociedade global. Sabemos agora que as duas tradiçôes mais antigas: o socialismo tradicional, com espaços na propriedade coletiva, e o gerenciamento econômico keynesiano não são mais relevantes. Mas também sabemos que não faz sentido tratar o mundo como um gigantesco mercado. A "segunda via" chegou a um beco sem saída. É uma filosofia incompleta, não tem uma justiça social. Procuramos uma política diferente (...). O que falamos é na modernização da centro-esquerda, modernização da filosofia e prática política da esquerda e centro. (Disponível em: <http://www.rodaviva.fapesp.br/>. Acesso em: 7 maio 2009)

Portanto, para Giddens (2007), a terceira via, também chamada de democracia social ou esquerda democratizadora, refere-se ao modo como os partidos de centro-esquerda respondem às mudanças. Verificase que a questão crucial permanece a mesma, de ser o centro, assumindo posições em alguns momentos mais à esquerda ou à direita, de propor reformas nos limites do capitalismo e com vistas a fortalecê-lo. 
Estado e terceiro setor: as novas regulações entre o público e o privado...

Vale ressaltar que, para a terceira via, a sociedade civil refere-se à parcela bem sucedida no mercado, uma vez que defende o fato de o Estado incentivá-la para que assuma as políticas sociais, por meio do empreendedorismo:

O empreendedorismo civil é qualidade de uma sociedade civil modernizada. Ele é necessário para que os grupos cívicos produzam estratégias criativas e enérgicas para ajudar na lida com problemas sociais. O governo pode oferecer apoio financeiro ou proporcionar outros recursos a tais iniciativas. (Giddens, 2007, p. 26)

$\mathrm{O}$ autor defende um novo modelo social europeu baseado no empreendedorismo, no investimento em tecnologia, no capital humano e na flexibilidade no mercado de trabalho. É possível observar que são princípios e açoes para países de bem-estar social consolidado, que, ao adaptarem-se aos ditames da reestruturação produtiva, aprofundarão os custos sociais e o aumento das desigualdades. Destaca-se que o agravamento das questões sociais é ainda maior em países que não tiveram o Estado de bem-estar social, como o Brasil, para onde esta agenda é simplesmente transposta.

O esvaziamento do conteúdo da democracia e a separação entre o econômico e o político são evidentes. Perdeu-se a discussão das políticas sociais como a materialização de direitos sociais. As lutas e conquistas dos anos de 1980 no Brasil, de direitos universais, deram lugar à naturalização do possível, isto é, se um Estado "em crise" não pode executar políticas, repassa para a sociedade civil e esta, por sua vez, focaliza as políticas sociais nos mais pobres para evitar o caos social. O Estado apenas repassa parte do financiamento, e avalia (Peroni, 2008a).

A especificidade do caso brasileiro no contorno de novas regulações entre o público e o privado

Assim, no Brasil, a identificação do Estado como responsável pela crise econômica está expressa no Plano Diretor da Reforma do Aparelho do Estado (PDRAE), elaborado pelo Ministério da Administração e Reforma do Estado, na gestão do ministro Luiz Carlos Bresser Pereira, e aprovado em 21 de setembro de 1995, pela Câmara da Reforma do Estado, no primeiro governo do presidente Fernando Henrique Cardoso (19951998). 
Segundo este Plano, a saída para a superação da crise é a reforma do Estado, como uma exigência imposta pela globalização econômica e uma necessidade premente para o país, com base nas seguintes estratégias: privatização - transferência para o setor privado das atividades que podem ser controladas pelo mercado; descentralização - transferência para o setor privado de serviços auxiliares ou de apoio; e publicização transformação de uma organização estatal em uma organização de direito privado, mas pública não-estatal (Bresser Pereira, 1998, p. 61).

Nesse sentido, a reforma deveria reorganizar o Estado, devido à crise fiscal que impede a sua capacidade de investimento; fortalecer o seu núcleo estratégico; assim como modificar o modelo de administração pública, ou seja, a administração pública burocrática deveria ser substituída pela administração pública gerencial (Brasil, 1995).

Este último aspecto é apresentado como solução para os problemas de clientelismo, burocratismo e patrimonialismo e obedece a critérios gerenciais de eficiência, o que significa, segundo essa perspectiva, “(...) devolver autoridade às unidades descentralizadas, dirigidas por novos tipos de funcionários: burocratas com capacidade gerencial. Significa controlar unidades descentralizadas através de resultados acordados, e não através de procedimentos detalhados” (Bresser Pereira, 2007 p. 528).

Além disso, atrela-se a viabilidade da reforma gerencial ao desempenho das organizações da sociedade civil de um duplo papel, ou seja: prover serviços sociais e científicos em bases competitivas e exercer o controle social. Nessa direção, cabe ao Estado transferir ao setor público nãoestatal (ou setor não-lucrativo) a execução de serviços sociais e científicos (escolas, hospitais, institutos de pesquisa), mantendo, no entanto, o seu papel social democrata de principal provedor de fundos (financiamento) para essas atividades. Em outras palavras: “(...) se a reforma gerencial significa descentralização e transferência, significa também controle de resultados por funcionários e políticos no centro estratégico do Estado, e controle social por parte da sociedade civil" (idem, ibid., p. 529).

Sob essa ótica, prevalece o entendimento de que, por um lado, sendo competitivos esses serviços serão mais eficientes do que os prestados pelas agências estatais; por outro, sendo públicos, porque estão direcionados para fins públicos, mais confiáveis do que os das empresas privadas na prestação de serviços, sobre os quais a informação é limitada. Segundo este entendimento, “(...) o que é estatal é em princípio 
Estado e terceiro setor: as novas regulações entre o público e o privado...

público. O que é público pode não ser estatal, se não faz parte do aparelho do Estado" (Bresser Pereira \& Grau, 1999 p. 6-17).

No modelo gerencial, portanto, a sociedade civil é representada pelo público não-estatal, pelo chamado terceiro setor (organizações não-governamentais [ONGs], instituições filantrópicas e comunitárias e outras associações similares). Estes organismos, criados com o objetivo de prover serviços sociais na área de saúde, educação, proteção contra o crime, transporte público, enfim, de alívio à pobreza, têm em comum o fato de serem não-lucrativos e fazerem parte da sociedade civil. Em outros termos:

(...) Existe algo de verdade nesta posição, mas é importante ver a sociedade civil como a sociedade organizada e ponderada de acordo com o poder que detenham os diversos grupos e indivíduos. A sociedade civil é, de fato, um conceito político, já que envolve poder. É formada por indivíduos com poder derivado de sua riqueza, de seu conhecimento, ou de capacidade organizadora, por organizaçôes corporativas e por entidades públicas não-estatais, do terceiro setor (...). (Idem, ibid., p. 19-20)

Assim sendo, em tempos de mundialização do capital e de redefiniçãao do papel do Estado, a terceira via remete à sociedade civil, ou melhor, ao terceiro setor, como estratégia para superar a crise, a responsabilidade pela implementação de políticas sociais (Peroni, 2008b), em nome da autonomia, da solidariedade, do altruísmo e do interesse geral, sendo que sua propagação é induzida e estimulada com subsídio público. Segundo esta ótica,

Fazem-se as reformas para colocar o Estado no diapasão do tempo: para conviver com uma sociedade mais informada, que toma crescentemente as contas do governo; com uma economia mais dinâmica e empresarial, que requer um Estado mais competente para ser estimulada e, tanto quanto necessário, orientada; e com uma cidadania mais ativa e solidária, que deseja não apenas usufruir de seus direitos, mas encontrar espaços públicos nos quais possa exercer seus deveres. (Cardoso, 1998, p. 11)

Desse modo, questiona-se o deslocamento do foco da participação da sociedade civil, enquanto controle social, entendido como mecanismo de acompanhamento das ações estatais, liberdade de associação, forma de ação democrática, para a execução das políticas sociais. Assim, a “(...) sociedade civil constitui não somente uma relação inteiramente 
nova entre o 'público' e o 'privado', mas um reino 'privado' inteiramente novo, com clara presença e opressão pública própria (...)” (Wood, 2003, p. 217-218).

Nessa perspectiva, a sociedade civil não é compreendida como cenário do embate político entre as classes, que levam a termo seus conflitos, como se não existissem antagonismos e luta contra-hegemônica, em uma sociedade capitalista marcada pela contradição e pelo confronto entre as classes.

Com base nessas considerações, importa reter a idéia de que é no contexto da reforma do Estado que o terceiro setor é estimulado a essa forma de participação, e no Plano Diretor da Reforma do Aparelho do Estado (Brasil, 1995) encontram-se os elementos centrais do chamamento e do desafio apresentados pelo governo para que este setor assuma a execução de políticas sociais e, assim, atue como espaço de transferência de responsabilidades estatais.

Em decorrência, tais ideias balizam a legislação que datam desse período, como a Lei das Organizaçôes Sociais (os), Lei n. 9.637, de 1998 (Brasil, 1998), do mesmo modo que a Lei das Organizaçôes da Sociedade Civil de Interesse Público (OSCIP), Lei n. 9.790 de 1999 (Brasil, 1999). Como assinala Cury (2007), apesar de terem elementos comuns, essas leis são diferentes. As organizações sociais são privadas, criadas pelo poder público e já nascem sob a forma de contrato de gestão de um patrimônio público. As organizações da sociedade civil de interesse público já eram privadas e se relacionam com o Estado por meio de parcerias. "Entretanto, a existência de ambas indica o fenômeno da publicização do Direito privado e da privatização do Direito público" (Cury, 2007, p. 8). Ainda, "(...) a essas associaçóes foram atribuídas maior rapidez na prestação de serviços, a capilaridade territorial e a continuidade aos programas" (idem, ibid.).

No que se refere à Lei n. 9.790/1999, cabe destacar que podem se qualificar como Organizaçôes da Sociedade Civil de Interesse Público as pessoas jurídicas de direito privado, sem fins lucrativos (art. $1^{\circ}$ ), que, por seu turno, têm acesso a recursos públicos para a realização de projetos, por meio da celebração de "termo de parceria" (Brasil, 1999). Assim, esta Lei criou o instrumento contratual denominado "termo de parceria", "firmado entre o Poder Público e as entidades qualificadas como OSCIP para a formação de vínculo de cooperação entre as partes, 
Estado e terceiro setor: as novas regulações entre o público e o privado...

no fomento de execução das atividades de interesse público, previstas no art. $3^{\circ}$ da Lei (...)", sendo este instrumento a sua grande inovação (Algebaile, 2005, p. 201).

Neste contexto, não se pode esquecer que os municípios brasileiros passaram a assumir, progressivamente, a oferta do ensino fundamental, tendo em vista o cumprimento das normas legais prescritas na Constituição Federal de 1988 e na Lei de Diretrizes e Bases da Educação Nacional (LDBEN), Lei n. 9.394/1996. E muitos deles buscaram, por meio de parcerias, alternativas no terceiro setor, para execução de políticas educacionais, no sentido de atender as suas demandas, superar os problemas educacionais e, principalmente, modernizar a gestão escolar, conforme mostram pesquisas em andamento. ${ }^{2}$

Adrião e Borghi (2008), por exemplo, analisam a tendência de consolidação de parcerias/convênios entre municípios paulistas e a iniciativa privada na área educacional, tomando como base os dados do Instituto Brasileiro de Geografia e Estatística (IBGE), de 2005, referentes aos municípios que têm algum tipo de apoio do setor privado ou de comunidades na área de educação. As autoras apontam que, da articulação de duas orientações complementares, ou seja, municipalização do ensino fundamental e alteraçôes no padrão de intervenção estatal,

(...) resultam inúmeros arranjos político-institucionais forjados pelas administrações municipais paulistas, para, na melhor das hipóteses, responder às demandas educativas assumidas. Num quadro de despreparo técnico e escassez de recursos, as consequências das opçóes governamentais parecem apontar para a introdução de mecanismos de privatização da educação municipal. (Adrião \& Borghi, 2008, p. 100)

Peroni (2008b), por sua vez, investiga a parceria entre o Instituto Ayrton Senna (IAS) e duas redes municipais do Rio Grande do Sul e observa, entre outros, as decorrências destas parcerias para a gestão da escola pública, de modo específico, os prejuízos para a gestão democrática historicamente construída pelos educadores brasileiros.

As implicações das novas regulações entre o público e o privado para a gestão da educação básica brasileira

No contexto de redemocratização da sociedade brasileira dos anos de 1980, a articulação entre educação e democracia foi reelaborada 
pelo pensamento educacional brasileiro. Este constructo apontava a educação como um canal possível de reconstrução de participação política, quando estaria sendo trabalhada por sistemas e unidades escolares a possibilidade de o ensino contribuir tanto com a construção de uma esfera pública, quanto com o alcance de um Estado de direito democrático social.

Essa perspectiva de articulação entre educação e democracia ganhou estatuto legal com a promulgação da Constituição Federal de 1988, que dispôs a gestão democrática entre os princípios do ensino. O princípio, normalizado pela legislação infraconstitucional, contudo, delegou aos sistemas de ensino a prerrogativa de sua construção e operacionalização.

Tal prerrogativa da gestão democrática da educação permitiu, desde então, que se construíssem experiências de gestão, principalmente das escolas, diferenciadas entre si: desde aquelas que se dispuseram a realizar eleições para diretores e colegiados, até aquelas em que a nomeação do diretor de escola ainda é prerrogativa do Poder Executivo, o que, segundo estudos da Confederação Nacional dos Trabalhadores em Educação (CNTE), se constitui em maioria (CNTE, 1999).

Outro importante marco erigido no contexto da articulação entre educação e democracia foi a possibilidade de construção pela escola de seu Projeto Político Pedagógico (PPP). Assim, o PPP estaria posto, entre outras situações, para repensar as relações e as estruturas de poder da escola em busca da superação do individualismo, da competitividade e do autoritarismo. Nesta perspectiva, o PPP seria o mecanismo pelo qual a escola, a partir de sua autonomia relativa, exercitaria suas possibilidades de participação coletiva, rompendo paulatinamente a separação entre concepção e execução, sendo entendido como "um instrumento de luta, uma forma de contrapor-se à fragmentação do trabalho pedagógico e sua rotinização, à dependência e aos efeitos negativos do poder autoritário e centralizador dos órgãos da administração central" (Veiga, 1997, p. 22).

Apesar desta trajetória de gestão de escola em andamento, a partir dos anos de 1990, no contexto de um novo padrão de acumulação ampliado do capital, que reordenou e redefiniu o papel do Estado e da política educacional, colocou-se para a gestão dos sistemas e das escolas um novo modelo orientado pelos princípios da gestão gerencial, com vistas a maior eficiência e eficácia ${ }^{3}$ do sistema. 
Estado e terceiro setor: as novas regulações entre o público e o privado...

Passou então a gestão democrática da educação a ser subsumida por outra lógica de gestão, que tomou como imperativo a persecução da administração por objetivos em escala organizacional, com fortes componentes de divisão do trabalho, de racionalidade instrumental e hierarquia estrutural, com vistas à qualidade total do setor educacional. Assim, no "campo educacional intensifica-se uma tendência de retomada do capital humano e de proposiçóes gerenciais como norte para as questões escolares, sobretudo nos processos de regulação e gestão dos diferentes níveis de ensino" (Dourado, 2004, p. 67).

Tal perspectiva de gestão da escola vem sendo passível de realização, em razão de que, no contexto da reforma do Estado brasileiro, a reforma da política educacional, objetivando a inserção competitiva do país, deliberou a centralidade da sua modernização. Este conceito de modernização sustenta o planejamento da gestão escolar em busca de resultados de eficiência e eficácia.

Pontua-se que a educação como prática social e, mais especificamente, a educação escolar foram alçadas à condição de lócus da construção de uma "nova pedagogia da hegemonia” (Neves, 2006), pois

Essa educação vem sendo propagada por diferentes meios, mas a escola continua sendo o espaço privilegiado para a conformação técnica e éticopolítica do "novo homem", de acordo com os princípios hegemônicos. O "novo homem", nessa visão de mundo, deve: sentir-se responsável individualmente pela amenização de parte da miséria do planeta e pela preservação do meio ambiente; estar preparado para doar uma parcela do seu tempo livre para atividades voluntárias nessa direção; exigir do Estado em senso estrito transparência e comprometimento com as questões sociais, mas não deve jamais questionar a essência do capitalismo. (Falleiros, 2005, p. 211)

Nesta nova pedagogia da hegemonia não se pretende historicizar as relações sociais; pelo contrário: busca-se a naturalização dos fenômenos para a conciliação social. Para tanto, este projeto educacional hegemônico descentralizou a gestão de sistemas e de unidades escolares, centralizou diretrizes curriculares, elevou a educação à condição de importante indicador econômico e social de forma centralizada, por meio de programas de avaliação em larga escala para a educação básica. Nesta conjuntura, foram importantes os rearranjos entre as unidades subnacionais - estados e municípios - e a União, que construíram processos 
de revisão entre as competências e as responsabilidades para os sistemas de ensino que culminaram em um amplo espectro de municipalização da educação básica, "motivados pela preocupação de atribuir relativa autonomia aos municípios e até mesmo às escolas para que possam captar mais recursos na fonte" (Oliveira, 1998, p. 97).

A eleição das prioridades educacionais, nesse contexto, reforça seu caráter privatizante, pois "o bem-estar social, que era tarefa do Estado, passa a se constituir em tarefa dos indivíduos e dos grupos" (Neves, 2005, p. 37). Diante disso, o projeto societário hegemônico expresso na política educacional traz o

(...) apelo à responsabilidade social, fundamentado na noção de sociedade civil enquanto espaço de ajuda mútua organicamente independente do Estado, consubstancia a estratégia da classe dominante e dirigente, sob a direção do que vem se denominando de liberal-socialismo ou socialismo-liberal, de radicalização da democracia, ou seja, de retração da participação popular aos limites de um pacto social no qual capital e trabalho procuram humanizar as relações sociais vigentes de exploração, expropriação e de dominação. (Idem, ibid., p. 38)

De fato, neste cenário, uma política educacional que expressasse a democracia enquanto participação política, no sentido de que as contradiçóes engendradas no âmbito econômico, político e social pudessem ser postas em sua desconstrução, à medida que tal participação fosse articuladora de lutas sociais, definitivamente, não compõe a agenda da política societária hegemônica.

Sabe-se que, entre a concepção e as práticas oriundas da articulação entre educação e democracia que permeiam a gestão da educação neste contexto, muito ainda se preserva de questôes, tais como o clientelismo, o paternalismo e o coronelismo políticos. Não obstante, é esta mesma prática que revela as contradições desse processo e que, por isso mesmo, tais práticas poderiam ser derrotadas, porque aflorariam do diálogo, do conflito e do embate das ideias.

A subsunção da gestão democrática à gestão gerencial, contudo, inverte essa lógica. A reforma do Estado, na perspectiva de sua retração para as políticas sociais e, particularmente, para a política educacional, destituiu a sociedade civil da participação política no sentido republicano. O que se conclama desde então é uma participação do tipo voluntariado, da ajuda mútua dos "amigos da escola", 
Estado e terceiro setor: as novas regulações entre o público e o privado...

enfim, das parcerias, uma vez que nestas estão as bases daquilo que se denominou como a participação pretendida pela terceira via e terceiro setor na lógica do público não-estatal. Em tal lógica, o ensino está sendo destituído da pedagogia da contestação, da transformação. Nesse lugar caberia agora a pedagogia da conformação e da conciliação imposta pelo pensamento hegemônico.

\section{Considerações finais}

Buscou-se, neste artigo, analisar as novas orientaçôes conferidas pelo projeto hegemônico à gestão da educação básica brasileira. Constatou-se que as estratégias de superação da crise do capitalismo, tais como a globalização, a reestruturação produtiva e o neoliberalismo, neste momento particular da história, impuseram como imperativo a reforma do Estado porque nele estaria o lócus da crise, conforme o projeto hegemônico.

Tal diagnóstico de crise foi possível a partir das elaborações teóricas do neoliberalismo e da terceira via, que engendraram novas reconfigurações entre público e privado, tecendo outras relaçóes no campo das políticas sociais, de forma geral, e da política educacional, particularmente.

No caso brasileiro, esse processo materializou-se por meio do Plano Diretor da Reforma do Aparelho do Estado (Brasil, 1995), que definiu as estratégias de privatização, descentralização e publicização (público não-estatal), tomando como um dos mecanismos de atuação a efetivação das parcerias entre o terceiro setor e os sistemas públicos de ensino.

Diante disso, para a gestão da educação básica, configurou-se a gestão gerencial da educação, mediante a substituição da incipiente gestão democrática da educação disposta na Constituição Federal de 1988 e normalizada pela Lei de Diretrizes e Bases da Educação Nacional (Lei n. 9.394/1996). Tal dispositivo de gestão engendra os ditames do projeto hegemônico, quando coloca outra concepção de participação da sociedade civil, pautada no controle social, com vistas à construção de uma pedagogia da hegemonia (Neves, 2006), que busca o consenso e a conciliação entre as classes sociais.

Como o diagnóstico proposto é o de que o Estado é o culpado pela crise, a lógica de mercado é que passou a ser sinônimo de qualidade. 
Essa lógica não é nova na educação e muitos pesquisadores já avançaram neste debate, como Rosar (1985), Paro (1993) e Dourado (2004), mostrando, ao contrário do que argumentam as teorias gerenciais, que o novo em gestão educacional é a gestão democrática. As teorias gerenciais em educação retornam ao debate a ideia de que o mercado é o padrão referencial para a escola, a diferença é embasada agora em um novo modelo de gestão, mas a lógica é a mesma.

Ao se discutir as novas orientações entre o público e o privado, neste período particular do capitalismo, e as suas consequências para a gestão da educação básica, entende-se que a gestão democrática da educação - processo ainda em construção -, em uma conjuntura de correlação de forças societárias em disputa, necessita voltar, mais uma vez, ao centro do debate educacional.

Recebido em julho de 2009 e aprovado em agosto de 2009.

\section{Notas}

1. Crise iniciada a partir dos anos de 1970 e intensificada no período atual.

2. As autoras participam da pesquisa "Análise das consequências de parcerias firmadas entre municípios brasileiros e a Fundação Ayrton Senna para a oferta educacional”, sob a coordenação da profa dra Theresa Adriāo, financiada pelo CNPq.

3. De acordo com Oliveira (1996), eficiência 'nessa concepção' seria “fazer um trabalho correto" e eficácia seria "aquele trabalho que atinge totalmente o resultado esperado".

\section{Referências}

ADRIÃO, T.; BORGHI, R. Parcerias entre prefeituras e esfera privada: estratégias privatizantes para a oferta da educação pública em São Paulo? In: Adriâo, T.; Peroni, V. Público e privado na educação: novos elementos para o debate. São Paulo, Xamã, 2008. p. 101-110.

ALGEBAILE, M.E.B. Mecanismos regulatórios como elementos constitutivos da nova pedagogia da hegemonia. In: Neves, L.M.W. (Org.). A nova pedagogia da hegemonia: estratégias do capital para educar o consenso. São Paulo: Xamã, 2005. p. 193-206.

ANTUNES, R. Os sentidos do trabalho: ensaios sobre a afirmação e a negação do trabalho. São Paulo: Boitempo, 1999. 
Estado e terceiro setor: as novas regulações entre o público e o privado...

BRASIL. (Constituição 1988). Constituição da República Federativa do Brasil. Diário Oficial da União, Brasília, DF, 5 out. 1988.

BRASIL. Câmara dos Deputados. Comissão de Educação, Cultura e Desporto. $L D B$ \& Lei do FUNDEF. Brasília, DF: Coordenação de Publicações, 2001.

BRASIL. Lei n. 9.637, de 15 de maio de 1998. Dispõe sobre a qualificação de entidades como organizações sociais, a criação do programa nacional de publicização, a extinção dos órgãos e entidades que menciona e a absorção de suas atividades por organizações sociais, e dá outras providências. Diário Oficial da União, Brasília, DF, 18 maio 1998.

BRASIL. Lei n. 9.790, de 23 de março de 1999. Dispõe sobre a qualificação de pessoas jurídicas de direito privado, sem fins lucrativos, como organizações da sociedade civil de interesse público, institui e disciplina o termo de parceria, e dá outras providências. Diário Oficial da União, Brasília, DF, 24 mar. 1999.

BRASIL. Ministério da Administração e Reforma do Estado. Plano Diretor da Reforma do Aparelho do Estado. Brasília, DF: MARE, 1995.

BRESSER PEREIRA, L.C. A reforma do Estado dos anos 90: lógica e mecanismos de controle. Lua Nova, São Paulo, n. 45, p. 49-95, 1998.

BRESSER PEREIRA, L.C. A nova esquerda: uma visão a partir do sul. In: Giddens, A. (Org.). O debate global sobre a terceira via. Trad. de Roger Maioli dos Santos. São Paulo: UnESP, 2007. p. 497-538.

BRESSER PEREIRA, L.C.; GRAU, N.C. Entre o Estado e o mercado: o público não-estatal. In: Bresser Pereira, L.C.; Grau, N.C. O público não-estatal na reforma do Estado. Rio de Janeiro: FGV, 1999. p. 15-47.

CARDOSO, F.H. Notas sobre a reforma do Estado. Novos Estudos CEBRAP, São Paulo, n. 50, p. 5-11, mar. 1998.

CONFEDERAÇÃO NACIONAL DOS TRABALHADORES EM EDUCAÇÃO. Retrato da escola 1. Disponível em: <http//:www.cnte.org. pesquisa/retratodaescola1>. Acesso em: 9 maio 2009.

CURY, C.R.J. Gestão democrática da educação em tempos de contradição. In: SIMPÓSIO BRASILEIRO DE POLÍTICA E ADMINISTRAÇÃO DA EDUCAÇÃO, 23., 2007, Porto Alegre. Anais Por uma 
escola de qualidade para todos: programação e trabalhos completos. Niterói: ANPAE; Porto Alegre: UfRGS/FACED/PPGEDU, 2007. p. 1-12. (1 CDROM).

DALE, R. A promoção do mercado educacional e a polarização da educação. Educação, Sociedade e Culturas, Porto, n. 12, p. 109-139, 1994.

DOURADO, L.F. Gestão democrática da escola: movimentos, tensões e desafios. In: Silva, A.M.M.; Aguiar, M.A.S. (Org.). Retrato da escola no Brasil. Brasília, DF: CNTE, 2004. p. 59-74.

FALLEIROS, I. Parâmetros curriculares nacionais para a educação básica e a construção de uma nova cidadania. In: Neves, L.M.W. (Org.). A nova pedagogia da hegemonia: estratégias do capital para educar o consenso. São Paulo: Xamã, 2005. p. 207-235.

GIDDENS, A. Entrevista Memória Roda Viva. São Paulo, 2000. Disponível em: <http://www.rodaviva.fapesp.br/materia/286/entrevistados/anthony_giddens_2000.htm>. Acesso em: 7 maio 2009.

GIDDENS, A. A terceira via: reflexôes sobre o impasse político atual e o futuro da social-democracia. Rio de Janeiro: Record, 2001.

GIDDENS, A. (Org.). O debate global sobre a terceira via. São Paulo: UNESP, 2007.

HARVEY, D. Condição pós-moderna. 4. ed. São Paulo: Loyola, 1989.

HARVEY, D. O neoliberalismo: história e implicações. São Paulo: Loyola, 2008.

MÉSZÁROS, I. A necessidade do controle social. São Paulo: Ensaio, 1987.

MÉSZÁROS, I. Para além do capital. São Paulo: Boitempo; Campinas: UNICAMP, 2002.

NEVES, L.M.W. (Org.). A nova pedagogia da hegemonia: estratégias do capital para educar o consenso. São Paulo: Xamã, 2006. p. 83-206.

NEVES, L.M.W.; PRONKO, M.A. O mercado do conhecimento e o conhecimento para o mercado. Rio de Janeiro: EPSJV, 2008.

PARO, V.H. Administração escolar: introdução crítica. São Paulo: Cortez, 1993. 
Estado e terceiro setor: as novas regulações entre o público e o privado...

PERONI, V.; ADRIÃO, T. Público não-estatal: estratégias para o setor educacional brasileiro. In: Adriāo, T.; Peroni, V. (Org.). O público e o privado na educação: interfaces entre Estado e sociedade. São Paulo: Xamã, 2005. p. 137-153.

PERONI, V.; ADRIÃO, T. Mudanças na configuração do Estado e sua influência na política educacional. In: PERONI, V.; BAZZO, V.L.; Pegoraro, L. (Org.). Dilemas da educação brasileira em tempos de globalização neoliberal: entre o público e o privado. Porto Alegre: UFRGS, 2006. p. 11-23.

PERONI, V.; ADRIÃO, T. Conselhos municipais de educação em tempos de redefinição do conceito democracia In: SouzA, D.B. Conselhos municipais e controle social da educação: descentralização, participação e cidadania. São Paulo: Xamã, 2008a.

PERONI, V.; ADRIÃO, T. A relação público/privado e a gestão da educação em tempos de redefiniçãao do papel do Estado. In: Adrião, T.; Peroni, V. Público e privado na educação: novos elementos para o debate. São Paulo, Xamã, 2008b. p. 111-127.

ROSAR, M.F.C.F. Administração escolar: um problema educativo ou empresarial. São Paulo: Cortez, 1985.

VEIGA, I.P.A. (Org.). Projeto político-pedagógico da escola: uma construção possível. 3. ed. Campinas: Papirus, 1997. p. 11-35.

WOOD, E.M. Democracia contra o capitalismo: a renovação do materialismo histórico. São Paulo: Boitempo, 2003. 